\title{
Genetic and antigenic analysis of invasive serogroup $C$ Neisseria meningitidis in Canada: A decrease in the electrophoretic type (ET)-15 clonal type and an increase in the proportion of isolates belonging to the ET-37 (but not ET-15) clonal type during the period from 2002 to 2009
}

\author{
Jianwei Zhou ${ }^{1}$ MSc, Frances Jamieson ${ }^{2,3}$ MD, Sharon Dolman ${ }^{4}$ RN MSc, Linda MN Hoang ${ }^{5}$ MSc MD,
} Prasad Rawte ${ }^{2}$ MSc, Raymond SW Tsang ${ }^{1}$ PhD

\begin{abstract}
J Zhou, F Jamieson, S Dolman, LMN Hoang, P Rawte, RSW Tsang. Genetic and antigenic analysis of invasive serogroup C Neisseria meningitidis in Canada: A decrease in the electrophoretic type (ET)-15 clonal type and an increase in the proportion of isolates belonging to the ET-37 (but not ET-15) clonal type during the period from 2002 to 2009. Can J Infect Dis Med Microbiol 2012;23(3):e55-59.
\end{abstract}

BACKGROUND: Serogroup C meningococcal disease has been endemic in Canada since the early 1990s, with periods of hyperendemic disease documented in the past two decades. The present study characterized invasive serogroup $\mathrm{C}$ meningococci in Canada during the period from 2002 to 2009

METHODS: Serogroup C meningococci were serotyped using monoclonal antibodies. Their clonal types were identified by either multilocus enzyme electrophoresis or multilocus sequence typing.

RESULTS: The number of invasive serogroup C Neisseria meningitidis isolates received at the National Microbiology Laboratory (Winnipeg, Manitoba) for characterization has dropped from a high of 173 isolates in 2001 to just 17 in 2009, possibly related to the introduction of the serogroup C meningococcal conjugate vaccine. Before $2006,80 \%$ to $95 \%$ of all invasive serogroup $\mathrm{C}$ meningococci belonged to the electrophoreic type (ET)-15 clonal type, and the ET-37 (but not ET-15) type only accounted for up to $5 \%$ of all isolates. However, beginning in 2006, the percentage of the ET-15 clonal type decreased while the ET-37 (but not ET-15) type increased from $27 \%$ in 2006 to $52 \%$ in 2009. The percentage of invasive serogroup $\mathrm{C}$ isolates not belonging to either ET-15 or ET-37 also increased. Most ET-15 isolates expressed the antigenic formula of C:2a:P1.7,1 or C:2a:P1.5. In contrast, the ET-37 (but not ET-15) isolates mostly expressed the antigens of C:2a:P1.5,2 or C:2a:P1.2.

CONCLUSION: A shift in the antigenic and clonal type of invasive serogroup $\mathrm{C}$ meningococi was noted. This finding suggests vigilance in the surveillance of meningoccocal disease is warranted.

Key Words: ET-15; ET-37; Meningococci; Serogroup C
L'analyse génétique et antigénique du Neisseria meningitidis invasif du sérogroupe $\mathrm{C}$ au Canada : une diminution du groupe clonal de type électrophorétique (ET)-15 et une augmentation de la proportion d'isolats appartenant au groupe clonal ET-37 (mais pas ET-15) entre 2002 et 2009

HISTORIQUE : La maladie à méningocoque du sérogroupe C est endémique au Canada depuis le début des années 1990, des périodes de maladie hyperendémique étant attestées depuis vingt ans. La présente étude caractérise des groupes de méningocoques invasifs du sérogroupe $\mathrm{C}$ au Canada entre 2002 et 2009.

MÉTHODOLOGIE : Les chercheurs ont sérotypé les méningocoques du sérogroupe $\mathrm{C}$ au moyen d'anticorps monoclonaux. Ils ont déterminé leur groupe clonal par électrophorèse d'enzyme multilocus ou par typage séquentiel multilocus.

RÉSULTATS : Le nombre d'isolats de Neisseria meningitidis invasifs du sérogroupe C envoyés au National Microbiology Laboratory de Winnipeg, au Manitoba, en vue de leur caractérisation a fléchi d'un pic de 173 isolats en 2001 à seulement 17 en 2009, peut-être en raison de l'adoption du vaccin conjugué contre le méningocoque du sérogroupe C. Avant 2006, de 80 \% à $95 \%$ de tous les méningocoques invasifs du sérogroupe $\mathrm{C}$ appartenaient au groupe clonal du type électrophorétique ET-15, et l'ET-37 (mais pas l'ET-15) ne représentait que jusqu'à $5 \%$ de tous les isolats. Cependant, à compter de 2006, le pourcentage de groupe clonal ET-15 a diminué, tandis que l'ET-37 (mais pas l'ET-15) est passé de $27 \%$ en 2006 à $52 \%$ en 2009. Le pourcentage d'isolats invasifs du sérogroupe C n'appartenant ni à l'ET-15 ni à l'ET-37 a également augmenté. La plupart des isolats d'ET-15 exprimaient la formule antigénique C:2a:P1.7,1 ou C:2a:P1.5. Par contre, les isolats d'ET-37 (mais pas d'ET-15) exprimaient surtout les antigènes C:2a:P1.5,2 ou C:2a:P1.2. CONCLUSION : Les chercheurs ont remarqué une transition du groupe antigénique et clonal des méningocoques invasifs du sérogroupe C. En raison de cette observation, il serait judicieux d'être vigilant en matière de surveillance de la maladie à méningocoque.

type (ET)-15, as determined by the technique of multilocus enzyme electrophoresis (MLEE) (3). Since the mid-1980s, there had been two brief periods (1989 to 1993 and 2000 to 2001) with increased incidence of IMD and, in both instances, it was associated with an increase in serogroup C disease due to the ET-15 clone (4). The first localized outbreak due to this clone was documented in the winter of 1988/1989 in Victoria County, Ontario (5). Since that time, it has

${ }^{1}$ Public Health Agency of Canada, Winnipeg, Manitoba; ${ }^{2}$ Ontario Agency for Health Protection and Promotion; ${ }^{3}$ Faculty of Medicine, University

of Toronto, ${ }^{4}$ Public Health Protection and Prevention Branch, Ontario Ministry of Health and Long-Term Care, Toronto, Ontario; ${ }^{5}$ Public

Health Microbiology and Reference Laboratory, British Columbia Centre for Disease Control, Vancouver, British Columbia

Correspondence: Dr Raymond Tsang, National Microbiology Laboratory, 1015 Arlington Street, Winnipeg, Manitoba R3E 3R2.

Telephone 204-789-6020, fax 204-789-2018, e-mail raymond.tsang@phac-aspc.gc.ca 
quickly spread to other parts of the country leading to implementation of intensive targeted vaccination campaigns in several provinces (Ontario, Quebec, Prince Edward Island and British Columbia) between 1991 and 1993 (6-9). Aside from causing an increase in the incidence of IMD in Canada (10) and the United States (11), ET-15 was also responsible for outbreaks in various parts of the world in the 1990s, including Israel, the Czech Republic, Iceland, Finland, Norway, England and Australia (12).

The ET-15 meningococci were identified by MLEE to be a member or subtype of the hypervirulent clone of the ET-37 complex, which has long been known to be associated with epidemic disease (13-15). The distinguishing feature of the ET-15 clone from the ET-37 clonal complex is the presence of a unique genetic allele for the housekeeping enzyme fumarase (fumC gene allele 2), which differs from that found in the ET-37 meningococci, which has the fumC gene allele 1. This difference in the fumC gene alleles, first observed by MLEE, has now been confirmed at the genetic level by a single base pair change (from $\mathrm{G}$ for allele 1 to A for allele 2) at position 640 of the fumC gene (16). Other than this change in the housekeeping enzyme fumarase, the original ET-15 variant that first appeared in Canada expressed the same antigenic formula (C:2a:P1.5,2) as members of the serogroup C ET-37 clonal complex (15).

In Canada, the vaccination campaigns launched after the initial appearance of the ET-15 clone were successful in reducing the extent of meningococcal disease between 1994 and 1999 (17,18). The meningococcal vaccines administered during the outbreaks were the bivalent $(\mathrm{A}, \mathrm{C})$ and the quadrivalent $(\mathrm{A}, \mathrm{C}, \mathrm{W}-135, \mathrm{Y})$ polysaccharide vaccines. While effective in reducing disease in the short term, these plain polysaccharide vaccines do not offer long-lasting immunity $(19,20)$. In 2000/2001, a second wave of serogroup C disease appeared, with the responsible ET-15 clone expressing genetic and antigenic variations (21) that might be responsible for the significant increases in meningococcal disease in some provinces, including British Columbia, Alberta, Manitoba, Ontario and Quebec (22). These variations in the serogroup C ET-15 meningococci included mutations in the serotype $2 \mathrm{a}$ antigen and recombination events in the PorA antigens (21). Since this second wave of serogroup C IMD, all provinces and territories have introduced a meningococcal serogroup C (MenC) conjugate vaccine into their routine immunization schedules for infants and school children (Public Health Agency of Canada, Provincial and territorial immunization programs <www.phac-aspc. gc.ca/ptimprog-progimpt/index.html>).

Surveillance studies performed after implementation of the Men-C conjugate vaccine policy have found a substantial decrease in serogroup C disease (23) as well as an indirect effect on herd immunity (24). However, during our routine laboratory characterization of serogroup C meningococci from IMD cases, we noticed early in 2006 a shift in invasive serogroup $\mathrm{C}$ meningococci from the ET-15 variant to the ET-37 (but not ET-15) type, such that by 2007, of all the serogroup C disease cases identified, more cases were caused by the ET-37 clone than by the ET-15 variant. Furthermore, we also noticed an overall slight increase in the proportion of serogroup $\mathrm{C}$ cases due to the nonET-15 and non-ET-37 clones. Therefore, the objective of the present study was to describe this temporal and geographic change and to discuss the potential implications of this shift in the genetic clone of invasive serogroup $\mathrm{C}$ meningococci in Canada. The present article also describes the characteristics of invasive serogroup $\mathrm{C}$ isolates in Canada during the period from 2002 to 2009.

\section{METHODS}

\section{Isolates}

Isolates of $\mathrm{N}$ meningitidis recovered from normally sterile body sites (eg, blood, cerebrospinal fluids, joint fluids, etc) of patients with IMD were provided by provincial public health laboratories across the country as part of the national strategy for surveillance of IMD in Canada (25). Serogrouping was performed at the local public health laboratories and confirmed at the National Microbiology Laboratory (NML).
In the current surveillance system for IMD, all provinces submit their IMD isolates to the NML via their provincial public health laboratories. Also, it has been estimated that isolates from $80 \%$ to $90 \%$ of IMD cases were submitted to the NML for analysis, and in recent years, the NML has also received isolates from IMD cases not reported to the National Notifiable Disease Surveillance System (26,27). In the present study, all invasive $N$ meningitidis isolates received at the NML during the period from 2002 to 2009 were included.

\section{Serotyping and serosubtyping}

Serotyping and serosubtyping of meningococci was performed by an indirect whole cell ELISA (28) with monoclonal antibodies to the following serotype and serosubtype antigens: 1, 2a, 2b, 4, 14, 15, 17, 19, P1.1, P1.2, P1.4, P1.5, P1.6, P1.7, P1.9, P1.10, P1.12, P1.13, P1.14, P1.15, P1.16 and P1.19 (Rijksinstituut voor Volksgezondheid en Milieu, National Institute of Public Health, Bilthoven, The Netherlands; and kind gifts from Dr WD Zollinger).

\section{Genetic characterization of strains}

Determination of the genotype of isolates before 2004 was performed by MLEE $(13,29)$ and, since 2004 , by multilocus sequence typing (MLST) (30). During 2004, MLST was conducted on all serogroup C $N$ meningitidis in parallel with MLEE, with the intention of replacing MLEE with MLST. For discrimination of the ET-15 variant from the ET-37 clone, extended DNA sequencing of the fumC gene was performed as described (16). In 2009, 20 serogroup C N meningitidis isolates that were formerly identified as ET-15 were retrieved from the NML strain collection and their identities as ET-15 were confirmed by MLST using the protocol described by Vogel et al (16). Throughout the present study, no disagreement was found between the results obtained by MLEE and MLST.

\section{RESULTS}

From 2002 to 2009, 294 serogroup C individual case isolates were recovered from IMD patients in Canada. The distribution of isolates by year according to the genetic clones of ET-15, ET-37 (but not ET-15) and non-ET-15/non-ET-37 is presented in Table 1. The clonal type of ET-15 was predominant among the invasive serogroup C isolates from 2002 to 2005 , accounting for $81 \%$ to $96 \%$ of all invasive serogroup C isolates collected. By 2006, the percentage of the ET-15 clonal type had decreased to $61 \%$, with further decreases to $48 \%$ observed in 2007, and 26\% in 2008. In 2009, the percentage of the ET-15 clonal type among all invasive serogroup C isolates was $35 \%$. Relative to the decrease in the ET-15 clonal type, the number of isolates and the percentage of the ET-37 (but not ET-15) clonal type increased from nine (27\%) in 2006 to $12(48 \%)$ in 2007, $18(67 \%)$ in 2008 and back to nine (53\%) in 2009. Aside from the overall temporal change in the numbers and percentages of ET-37 clonal type, geographical differences in the appearance of the ET-37 clonal type were also noticed. For example, in British Columbia, the increase of the ET-37 clonal type went from one case isolate in 2002 and 2005 to three, four and nine cases in 2006, 2007 and 2008, respectively. In Ontario, the increase was also from one case isolate per year in 2003 and 2005 to four, eight, two and eight cases in 2006, 2007, 2008 and 2009, respectively. Similar increases have not been observed in other provinces such as Alberta and Quebec (data not shown).

To examine if the shift from the ET-15 to non-ET-15 clonal type was related to certain antigenic types, the expression of serotype and serosubtype antigens in the ET-15 and the non-ET-15 isolates were compared (Table 2). While more (58\%) ET-15 isolates expressed the PorA antigens of P1.5 and P1.7,1; only $6 \%$ of the ET-37 (but not ET-15) isolates expressed these serosubtype antigens. On the contrary, $69 \%$ of the ET-37 (but not ET-15) isolates expressed PorA antigens of P1.2 and P1.5,2; while only $24.3 \%$ of the ET-15 isolates expressed these serosubtype antigens.

During this study period, 22 (8\%) of the 294 invasive serogroup C isolates were typed as neither ET-15 nor ET-37, and their characteristics 
TABLE 1

Invasive meningococcal disease (IMD) and clonal genetics of invasive serogroup C Neisseria meningitidis in Canada, from 2002 to 2009

\begin{tabular}{lccccc}
\hline & IMD & \multirow{2}{*}{$\begin{array}{c}\text { Cases due } \\
\text { cases*, }\end{array}$} & $\begin{array}{c}\text { Serogroup C } \\
\text { to }\end{array}$ & \multicolumn{3}{c}{ isolates belonging to } \\
\cline { 5 - 6 } Year & $\mathbf{n}$ & serogroup C & ET-15 & $\begin{array}{c}\text { ET-37 (but } \\
\text { not ET-15) }\end{array}$ & $\begin{array}{c}\text { Non-ET-15I } \\
\text { non-ET-37 }\end{array}$ \\
\hline 2002 & 186 & $72(39)$ & $69(96)$ & $2(3)$ & $1(1)$ \\
2003 & 145 & $36(25)$ & $29(81)$ & $2(6)$ & $5(14)$ \\
2004 & 156 & $45(29)$ & $41(91)$ & $0(0)$ & $4(9)$ \\
2005 & 164 & $39(24)$ & $34(87)$ & $2(5)$ & $3(7)$ \\
2006 & 154 & $33(21)$ & $20(61)$ & $9(27)$ & $4(12)$ \\
2007 & 186 & $25(13)$ & $12(48)$ & $12(48)$ & $1(4)$ \\
2008 & 158 & $27(17)$ & $7(26)$ & $18(67)$ & $2(7)$ \\
2009 & 173 & $17(10)$ & $6(35)$ & $9(53)$ & $2(12)$ \\
All years & 1322 & $294(22)$ & $218(74)$ & $54(18)$ & $22(8)$ \\
\hline
\end{tabular}

Data presetented as $n$ (\%) unless otherwise indicated. ${ }^{*}$ The number of IMD cases was based on the number of invasive $\mathrm{N}$ meningitidis isolates received at the National Microbiology Laboratory (Winnipeg, Manitoba). ET Electrophoretic type

are described in Table 3. The overall genetic and antigenic diversity among these 22 non-ET-15/non-ET-37 serogroup C isolates was in contrast to the ET-15 and ET-37 serogroup C meningococci. There were 14 different sequence types represented among these 22 isolates belonging to nine different clonal complexes.

\section{DISCUSSION}

$N$ meningitidis is known to have the capability to change and evolve via a number of genetic mechanisms, such as slipped-strand mispairing for phase variations in the expression of virulence factors such as capsule and lipo-oligosaccharide (31), inactivation of genes via insertion (or excision) of genetic mobile elements such as IS-1301 (32), and genetic mutations and recombinations $(33,34)$. Since the ET- 15 clone was first identified in Canada in 1986, variants of this clone have been described in subsequent years. These variants include a mutation hotspot identified in the serotype $2 \mathrm{a}$ antigen, which led to the phenotype of nonserotypeable $(35,36)$, PorA serosubtype antigenic variants expressing the antigenic formula of C:2a:P1.1,7 (37) and C:2a:P1.5 $(21,38)$, and capsule switching of the C:2a:P1.5,2 ET-15 to B:2a:P1.5,2 ET-15 $(39,40)$. Some of these antigenic changes have been implicated as potential causes of increased serogroup $\mathrm{C}$ disease activities in North America (21,41). Aside from the variability in the organism itself, incidences of IMD are known to fluctuate in an unpredictable cyclical pattern, which varies in different geographical regions, affected by the season, humidity and viral infections such as influenza (14). The frequency and distribution of the different serogroups responsible for causing IMD may also change over time (42).

As part of our routine laboratory surveillance activities, which include serogrouping, serotyping, serosubtyping and antibiotic susceptibility testing, all serogroup C isolates are also tested by either MLEE and/or MLST with extended DNA sequencing of the fumC gene to detect the ET-15 variant (16) to track the presence and prevalence of the ET-15 clone. The typing method of MLEE was introduced into our laboratory in the early 1990s when the first wave of serogroup C ET-15 disease appeared (3); before that, information about the clonal type of invasive serogroup $\mathrm{C}$ strains did not exist. However, since the ET-15 clonal type was identified, it has been the dominant type found in invasive serogroup $\mathrm{C}$ isolates in Canada. Even between the first and second waves of increased serogroup $\mathrm{C}$ disease activity, such as during periods of endemic disease (eg, in 1995 and 1996), 92\% of the invasive serogroup $\mathrm{C}$ isolates in Canada belonged to the ET-15 clonal type (17).

In the present study, we documented a change in the invasive serogroup $\mathrm{C}$ meningococci, with the ET-15 type being replaced by the ET-37 type. The decrease in the ET-15 clonal type appeared to be related to the sharp drop in serogroup $\mathrm{C}$ isolates expressing all
TABLE 2

Comparison of the serotype and serosubtype antigens among the electrophoretic type (ET)-15 and ET-37 (but not ET-15) serogroup $C$ invasive meningococci in Canada from 2002 to 2009

\begin{tabular}{lccc}
\hline & \multicolumn{3}{c}{$\begin{array}{c}\text { Isolates expressing the different antigenic } \\
\text { combinations among clonal groups }\end{array}$} \\
\cline { 2 - 4 } Antigens & ET-15 & $\begin{array}{c}\text { ET-37 } \\
\text { (but not ET-15) }\end{array}$ & ET-15 + ET-37 \\
\hline C:2a:P1.2 & $25(11)$ & $14(26)$ & $39(14)$ \\
C:2a:P1.5 & $52(24)$ & $2(4)$ & $54(20)$ \\
C:2a:P1.5,2 & $28(13)$ & $23(43)$ & $51(19)$ \\
C:2a:P1.7,1 & $74(34)$ & $1(2)$ & $75(28)$ \\
C:2a:P1.- & $19(9)$ & $9(17)$ & $28(10)$ \\
C:NT:P1.- & $6(3)$ & $2(4)$ & $8(3)$ \\
Others & $14(6)^{\star}$ & $3(6)^{\dagger}$ & $17(6)$ \\
All antigenic combinations, n & 218 & 54 & 272
\end{tabular}

Data presetented as $n$ (\%) unless otherwise indicated. *Includes two isolates each of C:2a:P1.15, C:NT:P1.2, C:NT:P1.5, and C:NT:P1.5,2; and one each of C:2a:P1.14, C:2a:P1.5,16; C:NT:P1.4; C:NT:P1.7,1; C:NT:P1.1, and C:NT:P1.-; ${ }^{\dagger}$ Includes two isolates of C:NT:P1.2, and one isolate of C:NT:P1.5,2

TABLE 3

Characteristics of non-electrophoretic type-37 invasive serogroup C meningococci in Canada from 2002 to 2009

\begin{tabular}{|c|c|c|c|c|c|}
\hline $\begin{array}{l}\text { Case } \\
\text { number }\end{array}$ & $\begin{array}{l}\text { Year of } \\
\text { isolation }\end{array}$ & Source & $\begin{array}{l}\text { Antigenic } \\
\text { formula }\end{array}$ & $\begin{array}{l}\text { Sequence } \\
\text { type }\end{array}$ & $\begin{array}{l}\text { Clonal } \\
\text { complex }\end{array}$ \\
\hline 1 & 2003 & Blood & C:14:P1.- & ST-437 & ST-41/44 \\
\hline 2 & 2004 & Blood/CSF & C:15:P1.9 & ST-571 & ST-41/44 \\
\hline 3 & 2005 & Blood & C:14:P1.- & ST-136 & ST-41/44 \\
\hline 4 & 2006 & Blood & C:NT:P1.10 & ST-34 & ST-32/ET-5 \\
\hline 5 & 2006 & Brain swab & $C: 4: P 1 .-$ & ST-33 & ST-32/ET-5 \\
\hline 6 & 2002 & Blood & $C: 4: P 1 .-$ & ST-4025 & ST-8/cluster A4 \\
\hline 7 & 2007 & CSF & $C: 2 b: P 1.2$ & ST-8 & ST-8/cluster A4 \\
\hline 8 & 2003 & CSF & $C: 17: P 1.19$ & ST-1095 & ST-269 \\
\hline 9 & 2003 & CSF & C:17:P1.19 & ST-269 & ST-269 \\
\hline 10 & 2004 & CSF & C:17:P1.19 & ST-269 & ST-269 \\
\hline 11 & 2005 & Blood & C:NT:P1.- & ST-60 & ST-60 \\
\hline 12 & 2006 & CSF & C:NT:P1.2,5 & ST-60 & ST-60 \\
\hline 13 & 2004 & Blood & $\mathrm{C:4:P1.13}$ & ST-278 & ST-35 \\
\hline 14 & 2004 & Blood & C:4:P1.- & ST-278 & ST-35 \\
\hline 15 & 2006 & Eye & C:4:P1.- & ST-278 & ST-35 \\
\hline 16 & 2008 & Blood & C:4:P1.- & ST-278 & ST-35 \\
\hline 17 & 2009 & Blood & C:15,19:P1.13 & ST-278 & ST-35 \\
\hline 18 & 2003 & Blood & C:NT:P1.6 & ST-4109 & ST-334 \\
\hline 19 & 2003 & CSF & C:NT:P1.6 & ST-4109 & ST-334 \\
\hline 20 & 2008 & Blood & C:NT:P1.9 & ST-4109 & ST-334 \\
\hline 21 & 2009 & Blood & C:NT:P1.5 & ST-2006 & ST-103 \\
\hline 22 & 2005 & Blood & C:1:P1.9 & ST-6209 & ST-212 \\
\hline
\end{tabular}

CSF Cerebrospinal fluid

antigenic types, and by 2009 there were only six invasive serogroup C ET-15 case isolates and four $(67 \%)$ of these were expressing the C:2a:P1.5 antigenic combination. In contrast, there were only two (3.6\%) C:2a:P1.5 isolates among the 55 invasive serogroup C ET-37 (but not ET-15) isolates, and the majority of the ET-37 (but not ET-15) isolates expressed the antigenic type of C:2a:P1.2,5, as originally described by Wang et al (15). Therefore, this shift from the ET-15 clonal type to the ET-37 (but not ET-15) clonal type appeared to also be associated with antigenic changes taking place in the invasive serogroup C isolates. Because we did not examine other virulence factors in our serogroup C ET-15 and ET-37 isolates, such as FetA and Opa proteins, it is uncertain whether there might be other changes associated with this genetic shift in the clonal type observed in the invasive 
serogroup C meningococci. A similar shift from the ET-15 variant to the ET-37 clonal type has not been reported in other parts of the world. This might be because the routine MLST protocol does not call for extended DNA sequencing of the fumC gene to cover the single point mutation site at position 640 that differentiates between ET-15 and ET-37 (16) and, therefore, such changes could have gone undetected elsewhere.

The overall percentage of the non-ET-15/non-ET-37 type also increased since our last study (43) (Table 3). In that study, with isolates recovered from 1999 to 2003, 15 (3.4\%) of 441 invasive serogroup C isolates belonged to the non-ET-15/non-ET-37 clonal type while in the present study, $22(9 \%)$ belonged to this category. It is also interesting to note that during the period from 1999 to 2003, one-third (five of 15) of the non-ET-15 and non-ET-37 serogroup C isolates belonged to the ST-8/cluster A4 clonal group, and since then, there has been only one additional ST-8/cluster A4 isolate recovered in 2007 from a serogroup C IMD case. Replacing the ST-8/cluster A4 was the ST-35 clonal complex as being the most common non-ET-15 and non-ET-37 clonal type among invasive serogroup $\mathrm{C}$ isolates, Five such isolates have been recovered since 2004, all of which belonged to the sequence type of ST-278. Isolates of ST-278 were not found in our previous study (1999 to 2003), although there were two isolates belonging to the ST-35 clonal complex and these two isolates, ST-35 and ST-4126, were recovered in 1999 and 2000, respectively. Finally, the three ST-269 isolates with the antigenic formula of C:17:P1.19 were related to an outbreak in Quebec in the winter of 2004/2005, which was due to an emerging clone of serogroup B meningococci ST-269 expressing the antigens B:17:P1.19 (44). It was interesting to note that this clone of ST-269 expressing the antigens of B:17:P1.19 first emerged in Quebec in the spring of 2003, and has expanded in subsequent years. These three serogroup C ST-269 isolates expressing antigens 17:P1.19 have been shown to be potential capsule switched strains (44), although it was not possible to determine whether the switch was from B:17:P1.19 to C:17:P1.19 or vice versa.

Although the present study was based on laboratory isolates collected passively from submitting provincial public health laboratories across the country, the sample of isolates collected in this system can be regarded as representative because we have been able to describe emerging clones $(36,37,44)$ as well as unusual isolates $(45)$ under this system of case isolates collection. Therefore, we believe that this shift in the invasive serogroup C strains in Canada is not due to a reporting or strain collection artifact.

\section{REFERENCES}

1. Varughese PV, Acres S. Meningococcal disease in Canada and serogroup distribution. Can Dis Wkly Rep 1983;9:177-80.

2. Varughese PV, Carter AO. Meningococcal disease in Canada. Surveillance summary to 1987. Can Dis Wkly Rep 1989;15:89-96.

3. Ashton FE, Ryan A, Borczyk A, Caugant DA, Mancino L, Huang D. Emergence of a virulent clone of Neisseria meningitidis serotype 2a that is associated with meningococcal Group C disease in Canada. J Clin Microbiol 1991;29:2489-93.

4. National Advisory Committee on Immunization. Statement on conjugated meningococcal vaccine for serogroups A, C, Y and W135. Can Commun Dis Rep 2007;33(ACS-3):1-23.

5. Helmann, GA, Mikel DE, Naus M, et al. Meningococcal disease in Ontario during the winter of 1988-89. Can Dis Weekly Rep 1989;15:59-62.

6. De Wals P, Dionne M, Douville-Fradet M, Bouliane N, Drapeau J, De Serres G. Impact of a mass immunization campaign against serogroup C meningococcus in the province of Québec, Canada. Bull WHO 1996;74:407-11.

7. Farley JD, Osei W. Invasive meningococcal disease, British Columbia December 1991-March 1992. Can J Public Health 1992;83:138-40.

8. Sweet L. The Prince Edward Island meningococcal immunization program. January - February 1992. Can J Public Health 1992;83:138-40.

9. Tolomeo O, Buffett C, Richardson E. Management of a cluster of cases of invasive group C Neisseria meningitidis infections in the Hamilton-Wentworth Region. Can Commun Dis Rep 1998;24:122-6.
Men-C conjugate vaccine was approved for use in Canada in 2001 (46), and routine Men-C conjugate vaccine programs have now been implemented in all jurisdictions in Canada, with most jurisdictions having implemented programs by 2005 and the remaining by 2007 (Public Health Agency of Canada, Provincial and Territorial Immunization Programs <www.phac-aspc.gc.ca/ptimprog-progimpt/ index.html $>$ ). The success of the Men-C conjugate vaccine programs resulted in a significant reduction in the number of invasive serogroup $\mathrm{C}$ isolates received and analysed at the NML from a high of 173 isolates in 2001 (47) to just 17 in 2009 (the present study). Although surveillance studies in the post-Men-C conjugate vaccine period did not show any capsule replacement $(23,24)$, most IMD cases in Canada are now caused by serogroup B strains (NML, unpublished data).

The significant antigenic and genetic diversity that exist in $N$ meningitidis and the ability of this organism to change may both contribute to its success as a human pathogen, although in most situations it exists in the upper respiratory tract as a harmless commensal to the human host (48). This remarkable adaptability of $N$ meningitidis should caution against any complacency in the monitoring of this human pathogen. The regular findings of unusual IMD isolates, such as the report of null mutants as causes of IMD (49), capsule switching and subcapsular antigenic shift $(21,41)$, unusual capsular antigens $(45,50)$ as well as the shift from a predominant ET-15 clonal type to the non-ET-15 form, as described in the present study, all speak to the need for continued vigilance in our surveillance of IMD.

ACKNOWLEDGEMENTS: The authors thank the directors and staff of the provincial public health laboratories for providing the isolates for the present study, and Dr WD Zollinger for his kind gifts of monoclonal antibodies to serotypes 17,19 and serosubtypes P1.19. The authors also thank Jan Stoltz for performing the MLEE analysis, Averil Griffith for performing serogrouping, serotyping and serosubtyping analysis, Marissa Cameron for performing MLST, and staff at the National Microbiology Laboratory's DNA Core Facility for their DNA sequencing work. This publication made use of the Neisseria Multi Locus Sequence Typing website <http://pubmlst.org/neisseria/> developed by Keith Jolley and ManSuen Chan and sited at the University of Oxford (Jolley KA, Chan MS, Maiden MCJ. mlstdbNet - distributed multilocus sequence typing (MLST) databases. BMC Bioinformatics 2004;5:86). The development of this site has been funded by the Wellcome Trust and European Union.

10. Whalen CM, Hockin JC, Ryan A, Ashton F. The changing epidemiology of invasive meningococcal disease in Canada, 1985 through 1992. JAMA 1995;273:390-4.

11. Jackson LA, Schuchat A, Reeves MW, Wenger JD. Serogroup C meningococcal outbreaks in the United States, an emerging threat. JAMA 1995;273:383-9.

12. Jelfs J, Munro R, Ashton FE, Caugant DA. Genetic characterization of a new variant within the ET-37 complex of Neisseria meningitidis associated with outbreaks in various parts of the world. Epidemiol Infect 2000;125:285-98.

13. Caugant DA, Zollinger WD, Mocca LF, et al. Genetic relationships and clonal population structure of serotype 2 strains of Neisseria meningitidis. Infect Immun 1987;55:1503-13.

14. Caugant DA. Population genetics and molecular epidemiology of Neisseria meningitidis. APMIS 1998;106:505-25.

15. Wang JF, Caugant DA, Morellli G, Koumare B, Achtman M. Antigenic and epidemiologic properties of the ET-37 complex of Neisseria meningitidis. J Infect Dis 1993;167:1320-9.

16. Vogel U, Claus H, Frosch M, Caugant DA. Molecular basis for distinction of the ET-15 clone within the ET-37 complex of Neisseria meningitidis. J Clin Microbiol 2000;38:941-2.

17. Deeks S, Kertesz D, Ryan A, Ashton F. Surveillance of invasive meningococcal disease in Canada, 1995-1996. Can Commun Dis Rep 1997;23:121-5.

18. Squires SG, Pelletier L, Mungai M, Tsang R, Collins F, Stoltz J. Invasive meningococcal disease in Canada, 1 January 1997 to December 31 1998. Can Commun Dis Rep 2000;26:177-82. 
19. Lepow ML, Goldschneider I, Gold R, Randolph M, Gotschlich EC. Persistence of antibody following immunization of children with groups $\mathrm{A}$ and $\mathrm{C}$ meningococcal polysaccharide vaccines. Pediatrics 1977;60:673-80.

20. MacDonald NE, Halperin SA, Law BJ, Forrest B, Danzig LE, Granoff DM. Induction of immunologic memory by conjugated vs plain meningococcal $\mathrm{C}$ polysaccharide vaccine in toddlers: A randomized controlled trial. JAMA 1998;280:1685-9.

21. Tsang RSW, Law DKS, Henderson AM, Cameron ML, Stoltz J. Increase in serogroup $\mathrm{C}$ meningococcal disease in Canada is associated with antigenic changes in the protein antigens of the ET-15 clone of Neisseria meningitidis. J Infect Dis 2006;194:1791-2.

22. Pollard AJ, Tam TWS. Statement on recommended use of meningococcal vaccines. Can Commun Dis Rep 2001;27:2-36.

23. Bettinger JA, Scheifele DW, Le Saux N, et al. The impact of childhood meningococcal serogroup $\mathrm{C}$ conjugate vaccine programs in Canada. Pediatr Infect Dis J 2009;28:220-4.

24. Kinlin LM, Jamieson F, Brown EM, et al. Rapid identification of herd effects with the introduction of serogroup $\mathrm{C}$ meningococcal conjugate vaccine in Ontario, Canada, 2000-2006. Vaccine 2009;27:1735-40.

25. Tsang RSW, Squires SG, Zollinger WD, Ashton FE. Distribution of serogroups of Neisseria meningitidis and antigenic characterization of serogroup Y meningococci in Canada, January 1, 1999 to June 30, 2001. Can J Infect Dis 2002;13:391-6.

26. Navarro C, Deeks SL, Medaglia A, Tsang RSW. Enhanced surveillance of invasive meningococcal disease in Canada: 1 January 2004, through 31 December, 2005. Can Commun Dis Rep 2007;33:1-15.

27. Watkins RM, Deeks SL, Medaglia A, Tsang RSW. Enhanced surveillance of invasive meningococcal disease in Canada: 1 January 2002, through 31 December, 2003. Can Commun Dis Rep 2006;32:97-106.

28. Abdillahi H, Poolman JT. Whole cell ELISA for typing Neisseria meningitidis with monoclonal antibodies. FEMS Microbiol Lett 1987;48:367-71.

29. Selander RK, Caugant DA, Ochman H, Musser JM, Gilmour MN, Whittman TS. Methods of multilocus enzyme electrophoresis for bacterial population genetics and systematics. Appl Environ Microbiol 1986;51:873-84.

30. Maiden MCJ, Bygraves JA, Feil E, et al. Multilocus sequence typing A portable approach to the identification of clones within populations of pathogenic microorganisms. Proc Natl Acad Sci USA 1998;95:3140-5.

31. Hammerschmidt, S, Muller A, Sillmann H, et al. Capsule phase variation in Neisseria meningitidis serogroup B by slipped-strand mispairing in the polysialyltransferase gene $(\mathrm{siaD})$ : Correlation with bacterial invasion and the outbreak of meningococcal disease. Mol Microbiol 1996;20:1211-20.

32. Hammerschmidt S, Hilse R, van Putten JP, Gerady-Schahn R, Unkmeir A, Frosch M. Modulation of cell surface sialic acid expression in Neisseria meningitidis via a transposable genetic element. EMBO J 1996;15:192-8.

33. Jolley KA, Wilson DJ, Kriz P, Mcvean G, Maiden MCJ. The influence of mutation, recombination, population history, and selection on patterns of genetic diversity in Neisseria meningitidis. Mol Biol Evol 2004;22:562-9.

34. van der Ende A, Hopman CTP, Dankert J. Multiple mechanisms of phase variation of PorA in Neisseria meningitidis. Infect Immun 2000;68:6685-90.
35. Law DKS, Henderson AM, Tsang RSW. DNA sequence analysis of the PorB protein of nonserotypeable serogroup C ET-15 meningococci suggests a potential mutational hot spot on their serotype antigens. J Clin Microbiol 2004;42:2718-23.

36. Tsang RSW, Kiefer L, Law DKS, et al. Outbreak of serogroup C meningococcal disease caused by a variant of Neisseria meningitidis serotype 2a ET-15 in a community of men who have sex with men. J Clin Microbiol 2003;41:4411-4.

37. Tsang RSW, Tsai CM, Zhu P, Ringuette L, Lorange M, Law DKS. Phenotypic and genetic characterization of a unique variant of serogroup C ET-15 meningococci (with the antigenic formula C:2a:P1.7,1) causing invasive meningococcal disease in Québec, Canada. J Clin Microbiol 2004;42:1460-5.

38. Patrick DM, Champagne S, Goh SH, et al. Neisseria meningitidis carriage during an outbreak of serogroup $\mathrm{C}$ disease. Clin Infect Dis 2003;37:1183-8.

39. Kertesz D, Coulthart M, Ryan A, Johnson W, Ashton F. Serogroup B, electrophoretic type 15 Neisseria meningitidis in Canada. J Infect Dis 1998;177:1754-7.

40. Tyler S, Tsang R. Genetic analysis of Canadian isolates of C:2a:P1.2,5 and B:2a:P1.2,5 Neisseria meningitidis strains belonging to the hypervirulent clone of ET-15. Can J Microbiol 2004;50:433-43.

41. Harrison LH, Jolley KA, Shutt KA, et al. Antigenic shift and increased incidence of meningococcal disease. J Infect Dis 2006;193:1266-74.

42. Keyserling HL, Pollard AJ, DeTora LM, Gilmet GP. Experience with MCV-4, a meningococcal, diphtheria toxoid conjugate vaccine against serogroups A, C, Y and W-135. Expert Rev Vaccines 2006;5:445-59.

43. Law DKS, Stoltz J, Henderson AM, Tsang RSW. Antigenic and genetic characterization of serogroup $\mathrm{C}$ meningococci isolated from invasive meningococcal disease cases in Canada from 1999 to 2003. Can J Microbiol 2005;51:523-30.

44. Law DKS, Lorange M, Ringuette L, et al. Invasive meningococcal disease in Québec, Canada, due to an emerging clone of ST-269 serogroup B meningococci with serotype antigen 17 and serosubtype antigen P1.19 (B:17:P1.19). J Clin Microbiol 2006;44:2743-9.

45. Tsang RSW, Tsai CM, Henderson AM, et al. Immunochemical studies and genetic background of two Neisseria meningitidis isolates expressing unusual capsule polysaccharide antigens with specifities of both serogroup Y and W135. Can J Microbiol 2008;54:229-34

46. National Advisory Committee on Immunization. Statement on recommended use of meningococcal vaccines. Canada Communicable Disease Report 2001;27(ACS-6):2-36.

47. Tsang RSW, Squires SG, Tam TWS. Characterization of Neisseria meningitidis strains isolated from invasive meningococcal disease cases in Canada in 2001. Can J Microbiol 2003;49:633-8.

48. Maiden MC. Population structure of Neisseria meningitidis. In: Ferreiros C, Criado MT, Vazquez J, eds. Emerging strategies in the fight against meningitis: Molecular and cellular aspects. Norwich, UK: Horizon Scientific Press, 2002:151-70.

49. Hoang LMN, Thomas E, Tyler S, et al. Rapid and fatal meningococcal disease due to a strain of Neisseria meningitidis containing the capsule null locus. Clin Infect Dis 2005;40:e38-42.

50. Claus H, Matsunaga W, Vogel U. Molecular discrimination between Neissseria meningitidis serogroups W-135 and Y based on the nucleotide recognition domain sequence of the capsule polymerases. J Clin Microbiol 2010;48:3459-60. 


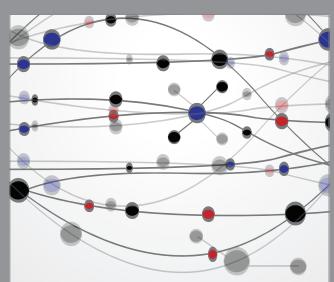

The Scientific World Journal
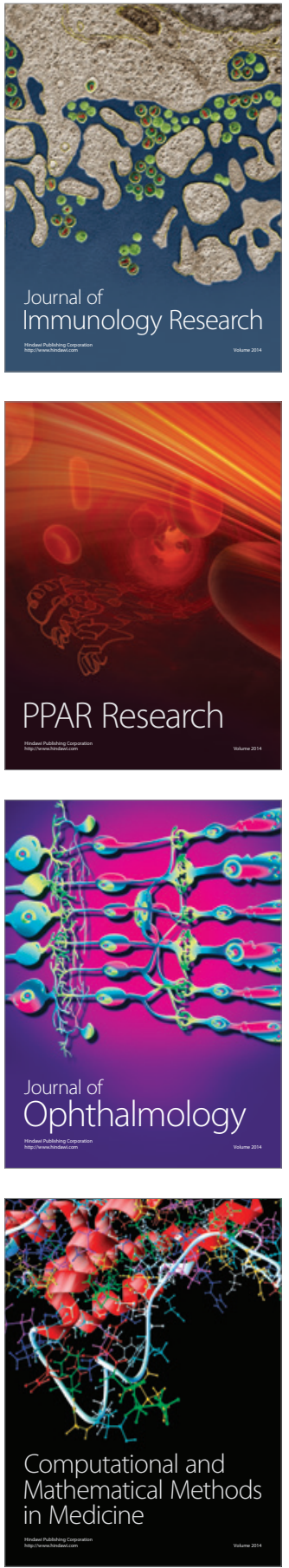

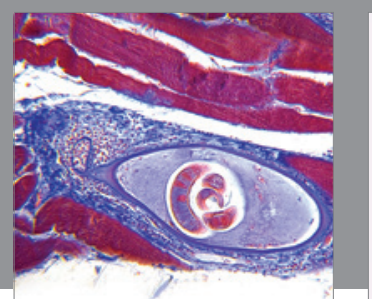

Gastroenterology Research and Practice

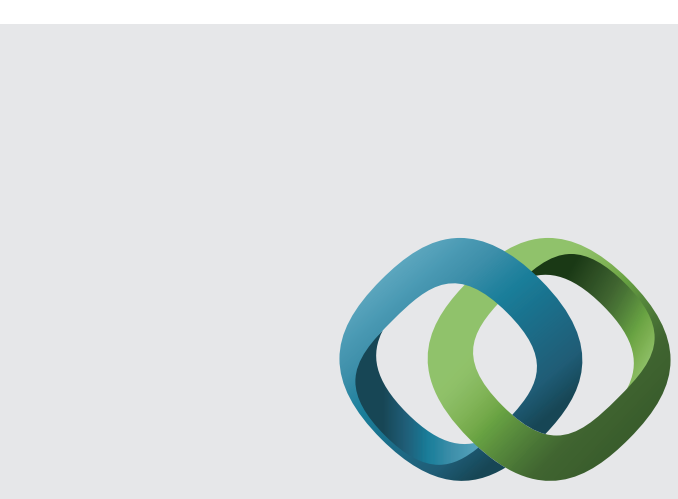

\section{Hindawi}

Submit your manuscripts at

http://www.hindawi.com
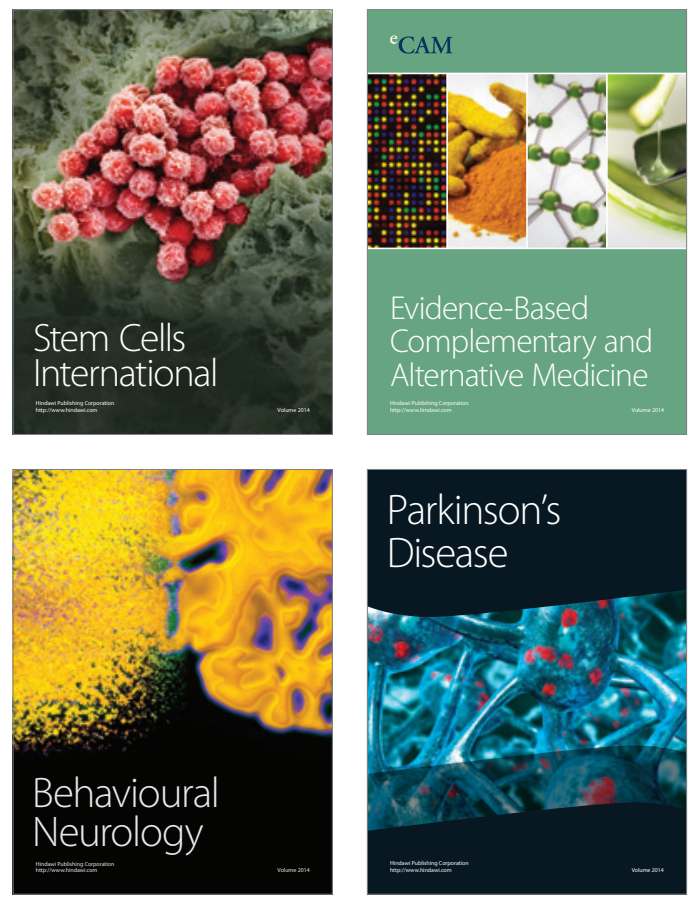
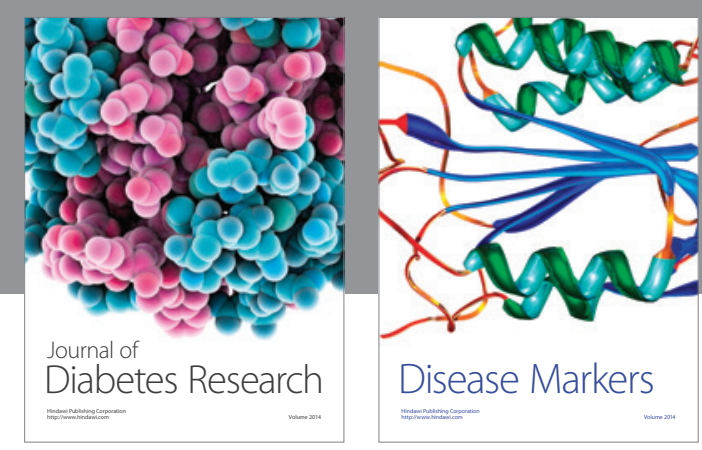

Disease Markers
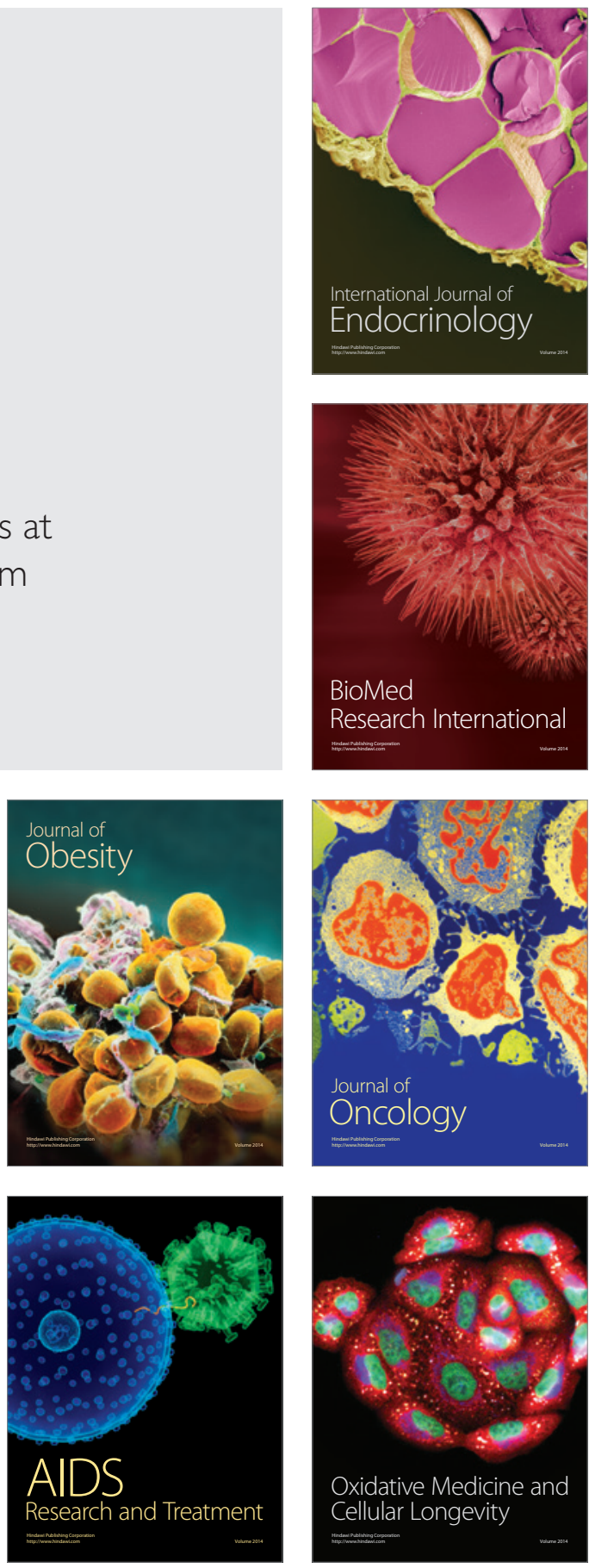